\title{
Synergistic inhibition of cyclooxygenases and monoacylglycerol lipase in neuropathic pain
}

\author{
Molly S. Crowe \\ West Virginia University
}

Follow this and additional works at: https://researchrepository.wvu.edu/etd

\section{Recommended Citation}

Crowe, Molly S., "Synergistic inhibition of cyclooxygenases and monoacylglycerol lipase in neuropathic pain" (2014). Graduate Theses, Dissertations, and Problem Reports. 515.

https://researchrepository.wvu.edu/etd/515

This Thesis is protected by copyright and/or related rights. It has been brought to you by the The Research Repository @ WVU with permission from the rights-holder(s). You are free to use this Thesis in any way that is permitted by the copyright and related rights legislation that applies to your use. For other uses you must obtain permission from the rights-holder(s) directly, unless additional rights are indicated by a Creative Commons license in the record and/ or on the work itself. This Thesis has been accepted for inclusion in WVU Graduate Theses, Dissertations, and Problem Reports collection by an authorized administrator of The Research Repository @ WVU. For more information, please contact researchrepository@mail.wvu.edu. 


\title{
Synergistic inhibition of cyclooxygenases and monoacylglycerol lipase in neuropathic pain
}

\author{
Molly S. Crowe \\ Thesis submitted to the Eberly College of Arts and Sciences at \\ West Virginia University \\ In partial fulfillment of the requirements for the degree of \\ Master of Science in Psychology/Behavioral Neuroscience
}

\author{
Steven G. Kinsey, Ph.D., Chair \\ Melissa Blank, Ph.D. \\ Karen G. Anderson, Ph.D. \\ Department of Psychology
}

Morgantown, WV

2013

Keywords: Neuropathic pain, chronic pain, endocannabinoid, mice, MAGL, dual administration, NSAID

Copyright 2013 Molly S. Crowe 


\title{
ABSTRACT \\ Synergistic inhibition of cyclooxygenases and monoacylglycerol lipase in neuropathic pain
}

\author{
Molly S. Crowe
}

Neuropathic pain is caused by altered nerve function that often presents as allodynia, which is the painful perception of typically non-noxious stimuli. Neuropathic pain is commonly treated with GABA analogues, steroids, or non-steroidal anti-inflammatory drugs (NSAIDs). NSAIDs inhibit one or more cyclooxygenase (COX) enzymes and are effective, commonly used analgesics that have relatively fewer side effects than other treatments. However, chronic cyclooxygenase inhibition also causes gastrointestinal inflammation and increased risk of cardiac events. Like NSAIDs, cannabinoids have analgesic and anti-inflammatory properties and reduce neuropathic pain in preclinical models. The present study investigated the analgesic effects of inhibiting both monoacylglycerol lipase (MAGL) and cyclooxygenase enzymes. Mice subjected to the chronic constriction injury (CCI) model of neuropathic pain were administered either the MAGL inhibitor, JZL184 (1-40 mg/kg, i.p.) or the nonselective COX inhibitor diclofenac sodium (1-100 mg/kg, i.p.) and tested for mechanical and cold allodynia. Then, both drugs were coadministered at various doses in ratios of 1:3, 1:1, and 3:1 parts of either compound. Isobolographic analyses revealed that combining low doses of JZL184 and diclofenac synergistically attenuated mechanical allodynia and additively reduced cold allodynia. These data support dual COX/MAGL inhibition as a promising therapeutic approach for neuropathic pain. 
SYNERGISTIC INHIBITION IN NEUROPATHIC PAIN

Table of Contents

Abstract............................................................................... 2

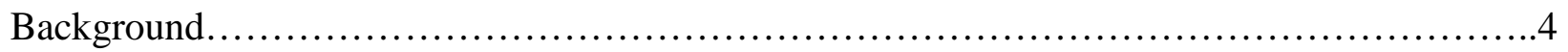

Neuropathic pain...........................................................4

Current pain treatments.......................................................

Endocannabinoid system................................................

Neuropathic pain model......................................................8

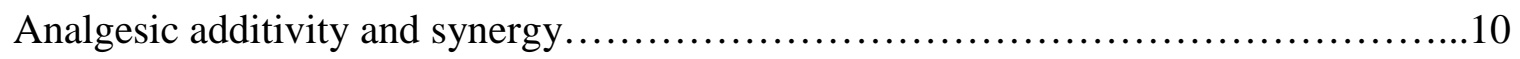

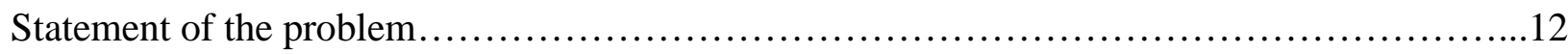

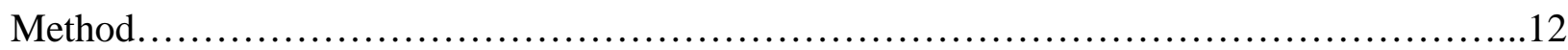

Animals.....................................................................12

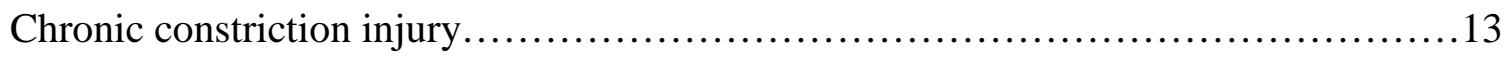

Behavior assessments....................................................13

Drugs................................................................... 14

Experimental plan.......................................................14

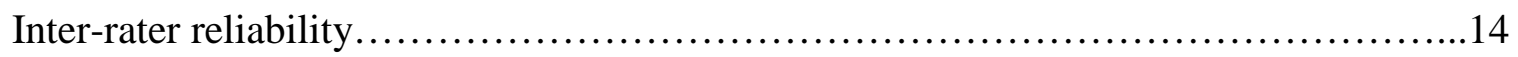

Statistical analysis.......................................................... 15

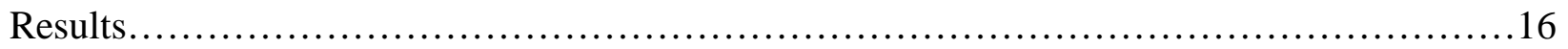

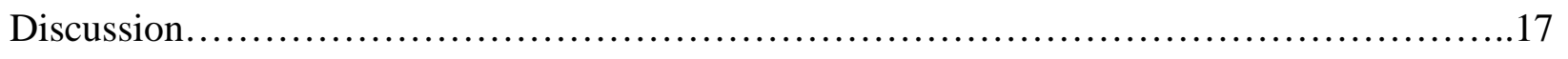

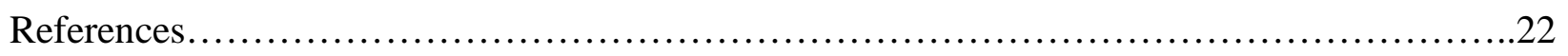

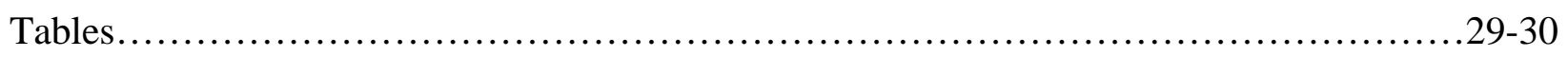

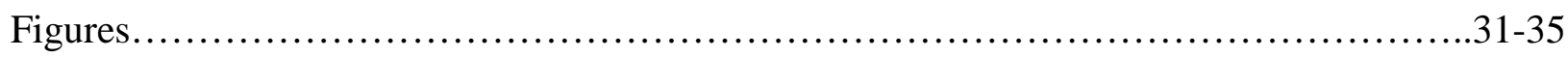


SYNERGISTIC INHIBITION IN NEUROPATHIC PAIN

\section{Background}

\section{$\underline{\text { Neuropathic Pain }}$}

Pain (i.e., nociception) has evolved to functionally serve as a warning sign of tissue damage or imminent threat of tissue damage to an individual. Pain can be broadly classified as either adaptive or maladaptive. Adaptive pain is produced by exceeding a noxious stimulus threshold, for example, by placing one's hand into an open flame. However, maladaptive forms of pain can develop when an injury remains unresolved, for example in the case of chronic inflammatory pain, or in cases where the pain circuits themselves are altered, as occurs with neuropathic pain.

Neuropathic pain is caused by a broad range of insults including peripheral nerve injury, autoimmune and other disease states, or toxic insult (Rahn \& Hohmann, 2009; Scholz \& Woolf, 2002; Zimmermann, 2001). In contrast to acute adaptive pain, neuropathic pain develops over a relatively long time and presents most commonly as spontaneous pain, hypersensitivity to noxious stimuli (i.e., hyperalgesia), or pain perception to non-noxious stimuli (i.e., allodynia). Because pain is vital for survival, the goal of any therapeutic approach is to reduce nociception to a manageable level, but not to eliminate the ability to feel any pain (i.e., antinociception).

Neuropathic pain decreases quality of life and is comorbid with decreased physical and emotional functioning, including depression, anxiety, sleep disturbances, social withdrawal, and physical constraints (Jensen, Chodroff, \& Dworkin, 2007; Sofaer-Bennett et al., 2007). Chronic pain conditions are associated with suicidal ideation which can be exacerbated by psychological comorbidities (Braden \& Sullivan, 2008). These interactions between physical and psychological pain highlight the need to develop new treatments for both pain and its associated emotional side

effects. Moreover, the psychological comorbidities elicited by chronic pain do not only affect the patient but the people surrounding the individual as well. Relationships can become strained due to the stressful nature of dealing with such a chronic affliction, as well as the aforementioned, associated emotional side effects (Sofaer-Bennett et al., 2007).

Although the emotional burden that neuropathic pain imposes on afflicted individuals and their caregivers is immeasurable, the economic burden of pain is somewhat easier to account for. These costs include the direct costs of medical care as well as indirect costs such as loss of productivity, disability, and decrease in work hours. Just in the United States, these costs are estimated to total around \$560-630 billion per year (IOM, 2011). In addition to this strain on the 
SYNERGISTIC INHIBITION IN NEUROPATHIC PAIN

U.S. economy, an estimated $\$ 2.6$ billion is spent on non-prescription analgesics including a class of enzyme inhibitors known broadly as non-steroidal anti-inflammatory drugs (NSAIDs) (Krueger \& Stone, 2008).

\section{Current Pain Treatments}

Neuropathic pain is difficult to treat and is often refractory to current pain treatments, including conventional analgesic medications. Given the well-documented side effects of traditional analgesics such as opioids, NSAIDs remain the most commonly used analgesics for neuropathic pain (although many other forms of chronic pain are also resistant to NSAIDs). Acetylsalicylic acid (aspirin) is the prototypical NSAID and has been used in humans for over 100 years (Lanas, 2009). Aspirin is used worldwide as an inexpensive analgesic and cardioprotective agent (Lanas, 2009). Currently, there are manifold NSAID treatments including diclofenac sodium, ibuprofen, and naproxen (Lanas, 2009; Patrono \& Baigent, 2009). The availability of numerous NSAIDs having the same mechanism of action suggests high pharmacokinetic variability among drugs and an inconsistency in effective treatment (Patrono \& Baigent, 2009).

Notably, the side effects of NSAIDs are less severe than many other pain treatments, such as opioids. As effective as NSAIDs may be as analgesics, chronic NSAID use may cause severe gastrointestinal bleeding side effects, which are potentially life-threatening, especially in the elderly, who are also more likely to use NSAIDs regularly for a range of chronic pain and/or inflammatory conditions (Musumba, Pritchard, \& Pirmohamed, 2009).

NSAIDs decrease pain and inflammation by inhibiting cyclooxygenase (COX-1 and COX-2) enzyme activity, subsequently blocking prostaglandin synthesis. Prostaglandins are lipids that are produced throughout the body and modulate physiological processes including inflammation. Prostaglandins in the GI tract regulate and maintain gastric mucosa and gastric acid secretions (Singh, 1998). COX-1 is constitutively produced, provides homeostatic functions, and regulates the gastric mucosa (Rouzer \& Marnett, 2009), while COX-2 is induced by tissue injury and is involved in regulating inflammation (Viegas, Manso, Corvo, Marques, \& Cabrita, 2011). Although inhibiting COX-1 has acute anti-inflammatory effects, it paradoxically causes GI inflammation by altering regulatory prostaglandins levels. For example, causing gastric hemorrhages by one or more mechanisms can result in hindered gastric endothelial cell renewal 
SYNERGISTIC INHIBITION IN NEUROPATHIC PAIN

and delayed healing of the stomach (Musumba et al., 2009). The severity of side effects increases with age and can be predicted to some degree by the patient's medical history (Raffa, 2001).

In order to circumvent the GI side effects caused by nonselective COX inhibitors, highly selective cyclooxygenase-2 isozyme inhibitors called coxibs were developed over 10 years ago. Although coxibs potently reduced pain and inflammation without GI side effects in humans (FitzGerald \& Patrono, 2001), they also increased the risk of major vascular complications, especially heart attacks (Patrono \& Baigent, 2009). Coxibs remain on the market, however the controversy sparked by these COX-2 selective enzyme inhibitors has weakened enthusiasm for their widespread use.

In addition to NSAIDs, other classes of drugs used to treat neuropathic pain include opioids, antidepressants, and antiepileptics. Opioids, including morphine, methadone, and oxycodone, have analgesic effects that persist through long-term treatment ( 28 days), whereas short-term trials (less than eight hours) produce mixed results in humans (Eisenberg, McNicol, \& Carr, 2006). Opioids also have well-characterized side effects that do not attenuate after repeated administration. Patients treated with opioids may experience nausea, constipation, dizziness, drowsiness, or vomiting (Eisenberg et al., 2006). Opioids are also accompanied with a high potential for abuse and drug dependence, lessening their appeal for routine use. Moderate analgesic effects of the anti-depressant serotonin-noradrenaline reuptake inhibitors (SNRIs) have been documented, whereas selective serotonin reuptake inhibitors (SSRIs) are inadequate for pain relief (Attal et al., 2006). The most effective antiepileptics for neuropathy are gabapentin (a gamma-Aminobutyric acid (GABA) analogue) and pregabalin (Attal et al., 2006). However, these drugs also have adverse side effects including drowsiness, dizziness, and ataxia (Beal, Moeller-Bertram, Schilling, \& Wallace, 2012).

Given the intractable nature of neuropathic pain and the previously mentioned side effects of current treatments, some patients self-medicate with drugs of abuse, including Cannabis. Cannabis has been used for at least four thousand years to treat many medical and emotional conditions, including pain (Mechoulam \& Parker, 2012). In humans, Cannabis attenuates a multitude of disease symptoms including those of cancer, multiple sclerosis, neurodegenerative diseases, and other chronic pain states (Kogan \& Mechoulam, 2007). Human immunodeficiency virus (HIV) patients have reported benefiting from Cannabis in appetite, muscle pain, nausea, anxiety, neuropathic pain, depression, and paresthesia (Woolridge et al., 
SYNERGISTIC INHIBITION IN NEUROPATHIC PAIN

2005). Since the primary psychoactive constituent of Cannabis, $\Delta^{9}$-tetrahydrocannabinol (THC), was first identified nearly 50 years ago (Gaoni \& Mechoulam, 1964) many other cannabinoids have been identified and cloned. Cannabinoids inhibit neuronal transmission in pain pathways, thereby reducing pain (Kogan \& Mechoulam, 2007). Because of its antiemetic and prophagic effects, a synthetic, oral preparation of THC, dronabinol, is currently approved by the Food and Drug Administration for the treatment of chronic wasting conditions.

As with opioids, although there are advantages to using Cannabis as an analgesic treatment, there are considerable concerns about dependence and psychomimetic effects. Cannabis can cause unwanted behavioral and cognitive effects. These consist of attention, memory, and motor deficits, but can also increase the risk of schizophrenia-like psychoses (Kogan \& Mechoulam, 2007). To avoid these negative side effects, and also to better understand the biological mechanisms involved in the many processes that cannabinoids affect, current research focuses on the endogenous cannabinoid (i.e., endocannabinoid; eCB) system. The endocannabinoid system is involved in many neurobehavioral processes, including pain, inflammation, learning, memory, energy, and feeding regulation (Lichtman, Blankman, \& Cravatt, 2010).

\section{Endocannabinoid System}

Two eCB receptor subtypes have been identified and cloned, cannabinoid receptor 1 $\left(\mathrm{CB}_{1}\right)$ and cannabinoid receptor $2\left(\mathrm{CB}_{2}\right) . \mathrm{CB}_{1}$ is expressed throughout the body and is implicated in the neurobiological effects of cannabinoid agonists, including hypothermia, immobility, and cognitive deficits (Herkenham et al., 1991). Selective $\mathrm{CB}_{1}$ receptor antagonists block the psychoactive effects of THC (Wise, Thorpe, \& Lichtman, 2009). CB $_{2}$ receptors are expressed predominately on immune cells but have recently been identified in the central nervous system, particularly in the brain stem and on microglia, which function as immune cells of the nervous system (Mechoulam \& Parker, 2012). The two endogenous cannabinoids, $N$ arachidonylethanolamine (anandamide; AEA) and 2-arachidonylglycerol (2-AG), bind to and activate both cannabinoid receptors (Ahn, McKinney, \& Cravatt, 2008). Brain levels of 2-AG are approximately 200-fold higher than anandamide levels (Kinsey et al., 2011). Oleoylethanolamide (OEA) and palmitoylethanolamide (PEA) are also considered endocannabinoids, however they have low affinity for $\mathrm{CB}_{1}$ and $\mathrm{CB}_{2}$ receptors, and bind only at very high concentrations in vitro 
SYNERGISTIC INHIBITION IN NEUROPATHIC PAIN

(Lambert et al., 1999; Sheskin, Hanus, Slager, Vogel, \& Mechoulam, 1997), thus casting doubt on their physiological relevance.

An interesting characteristic of endocannabinoids is that, unlike most neurotransmitters, endocannabinoids are retrograde messengers. For example, 2-AG is synthesized in the postsynaptic neuron, from which it travels backwards across the synapse and binds with the receptor on the presynaptic neuron (Mechoulam \& Parker, 2012). Although some controversy exists over whether anandamide acts in the same retrograde way, this retrograde transmission parallels the general inhibitory effects of eCBs in neural networks. Another unusual characteristic of endocannabinoids as neurotransmitters is that they are synthesized on demand and are not stored in vesicles in the axon terminus, due to their lipophilic nature (Mechoulam \& Parker, 2012).

Endocannabinoid levels are tightly regulated in vivo by synthetic and metabolic enzymes. Fatty acid amide hydrolase (FAAH) and monoacylglycerol lipase (MAGL) regulate anandamide and 2-AG, respectively. These enzymes metabolize their target endocannabinoids, resulting in shortened activity. Arachidonic acid is a metabolite of both anandamide (with ethanolamine) and 2-AG (with glycerol). Exogenous administration of the endocannabinoids is therapeutically ineffective due to the rapid degradation by FAAH and MAGL in vivo. However, the genetic deletion or pharmacological inhibition of MAGL or FAAH increases brain levels of 2-AG or anandamide causing analgesia (Kinsey et al., 2009; Lichtman, Shelton, Advani, \& Cravatt, 2004; Long et al., 2009).

Neuropathic Pain Model

Animal models of neuropathic pain are used to better understand the neurobiological etiology of the disease states as well as possible therapeutic treatments. The best characterized mouse model of neuropathic pain uses partial ligation of the sciatic nerve, and is known as chronic constriction injury (CCI). After the nerve ligation, immune cells at the injury site and glia in the dorsal root ganglia of the spinal cord located ipsilateral to the injury produce proinflammatory cytokines, which then activate other immune cells to permeate the injured area (McMahon, Cafferty, \& Marchand, 2005). The inflammatory response initiated by CCI causes mechanical and cold allodynia in the paw that is ipsilateral to the nerve injury, while the paw that is contralateral to the injury is unaffected by the surgery (Table 1) and may be used as a control, thus reducing the number of animals required in this model. In experimental animal models of 
SYNERGISTIC INHIBITION IN NEUROPATHIC PAIN

pain, allodynia is operationally defined by various behavioral responses to paw stimulation that involve the mouse lifting its paw off the testing table. Similarly, patients suffering from neuropathic pain report an increase in touch and cold sensitivity, thus increasing the clinical relevance of CCI as an experimental animal model of neuropathic pain (Attal et al., 2006). CB $_{1}$ receptor expression in the spinal cord increases after CCI surgery in rats (Lim, Sung, Ji, \& Mao, 2003), further demonstrating pain modulation by eCB is a promising treatment of pain perception behaviors.

As mentioned above, manipulation of endocannabinoids in vivo is possible via selective inhibition of endocannabinoid metabolic enzymes. For example, PF-3845 and JZL184 are pharmacological compounds that inhibit FAAH and MAGL, respectively (Figure 1). FAAH or MAGL inhibition prevents the breakdown of anandamide or 2-AG, which leads to increased brain levels of either eCB, resulting in cannabinoid receptor mediated analgesia. Administration of either compound decreases mechanical and cold allodynia in mice (Kinsey et al., 2009; Kinsey, O’Neal, Long, Cravatt, \& Lichtman, 2011). FAAH or MAGL inhibition significantly attenuates mechanical and cold allodynia in the CCI model (i.e., decreasing paw lifting) in mice. Unlike the exogenous cannabinoid THC, JZL184 and PF-3845 have no effect on locomotor activity, indicating that their analgesic effects are not due to sedation (Kinsey, O'Neal, et al., 2011). $C_{1}$ and $C B_{2}$ antagonists reverse the anti-allodynic effects of FAAH inhibitors in the CCI model (Kinsey et al., 2009; La Rana et al., 2008; Russo et al., 2007). Conversely, the antiallodynic effects of JZL184 were only blocked by the CB $_{1}$ antagonist rimonabant (SR141716A), indicating that MAGL inhibition reduces neuropathic pain via a mechanism involving $\mathrm{CB}_{1}$, but not $\mathrm{CB}_{2}$, receptors (Kinsey et al., 2009). JZL184 also increases brain level of 2-AG after oral administration in mice (Long et al., 2009), increasing the clinical applicability of MAGL inhibition as a potential therapeutic target.

In contrast to opioids, non-human primates do not self-administer the FAAH inhibiter URB597, indicating that inhibition of endocannabinoid enzymes is a feasible therapeutic option for attenuating pain, with reduced abuse potential (Justinova et al., 2008). 
SYNERGISTIC INHIBITION IN NEUROPATHIC PAIN

\section{Analgesic Additivity and Synergy}

Combining drugs with different mechanisms of action can produce greater pain attenuation than individually administered analgesics (Raffa, 2001). This dual administration approach may allow for subclinical dose of each drug, thereby lessening the side effects of each compound while maintaining adequate pain relief (Guindon, Walczak, \& Beaulieu, 2007). This type of broader coverage of multiple mechanisms is used successfully in the treatment of diseases such as HIV, diabetes, and hypertension, and, thus, pair dosing may also be effective for neuropathic pain treatments (Raffa, 2001; Tallarida, 2011).

Pair dosing of drugs with similar experimental outcomes can produce results that are less than (subadditive), equal to (additive) or greater than (synergistic) individual effectiveness of either compound (Tallarida, 2011). For example, a subadditive drug interaction would have an antagonistic effect, resulting in lower expected effects than either drug when administered alone. On the other hand, an additive drug interaction is when dual administration results in an effect that is very similar or equal to the sum of the expected effects of each of the individual drugs when administered alone. Finally, a drug interaction is considered to be synergistic when the result of the amalgamation is above the singular expected efficacy of the sum of the effects of each drug.

When looking for synergism, each drug must have similar individual potency in order to contribute to the combined effects (Tallarida, 2011). Endocannabinoid enzyme inhibitors and NSAIDs attenuate allodynia via distinct physiological mechanisms. As detailed above, NSAIDs block prostaglandin synthesis by inhibiting COX-1 and/or COX-2, whereas JZL184 selectively inhibits MAGL, thus increasing the endocannabinoid 2-AG, which binds to $\mathrm{CB}_{1}$ receptors. Unpublished, preliminary data from our lab show the nonselective COX inhibitor diclofenac partially attenuates mechanical and cold allodynia in mice subjected to CCI. Kinsey and colleagues (2009) demonstrated that the MAGL inhibitor JZL184 attenuates mechanical and acetone-induced cold allodynia. For the present study, these results were replicated and extended, testing the anti-allodynic effects of a range of doses of JZL184 and diclofenac in mice subjected to CCI. Therefore, COX and endocannabinoid modulators are viable candidates for testing synergistic effects.

While reducing pain via separate mechanisms, eCB enzyme inhibitors and NSAIDs do have a potential common pathway that may contribute to their potential synergistic analgesia: 
SYNERGISTIC INHIBITION IN NEUROPATHIC PAIN

arachidonic acid. Arachidonic acid is a precursor for prostaglandin synthesis. FAAH and MAGL inhibitors both block the breakdown of endocannabinoids into arachidonic acid, and NSAIDs obstruct COX from synthesizing prostaglandins from arachidonic acid (Rouzer \& Marnett, 2009). When given together, NSAIDs and MAGL inhibitors could work congruently to have an enhanced effect over the standard monoadministration (Nomura et al., 2011). There is evidence for such synergy. Indeed, at high doses, COX inhibitors also inhibit FAAH, thereby blocking the metabolism of the exogenous anandamide resulting in reduced pain responses (Guindon \& Beaulieu, 2006), although this is not the primary mechanism through which COX inhibitors attenuate pain.

Previous research has evaluated synergy in dual administration of NSAIDs and anandamide modulators. Coadministration of the NSAID diclofenac and the FAAH inhibitor URB597 in equipotent low doses synergistically attenuated acute visceral pain, which was measured by number of stretching responses elicited by the intraperitoneal injection of dilute acetic acid (Naidu, Booker, Cravatt, \& Lichtman, 2009). Combined administration of diclofenac and URB597 synergistically reduced the number of stretches. Local administration of exogenous anandamide combined with a COX inhibitor (COX-2 selective, as well as non-selective COX inhibitors were used), reduced thermal hyperalgesia and mechanical allodynia induced by partial sciatic nerve ligation in rats (Guindon \& Beaulieu, 2006). Another potent FAAH inhibitor, URB937, was combined with the NSAID diclofenac sodium to synergistically reduce mechanical and thermal hyperalgesia and mechanical allodynia in models of inflammatory and neuropathic pain (Sasso et al., 2012). Subclinical doses of these drugs interacted synergistically to significantly decrease pain responses in all three models of pain. Taken together, these studies comparing COX and FAAH inhibitors support the idea of potential synergy between an NSAID and a MAGL inhibitor to reduce the observed paw lifts in mice.

The present study was designed to investigate the possible synergy between the MAGL inhibitor JZL184 and the COX inhibitor diclofenac sodium. This study sought to determine whether the synergistic effects of endocannabinoid and COX modulation extend beyond acute visceral and local pain models, as have been previously demonstrated. In addition, this study extended previous findings by focusing on the MAGL inhibitor JZL184, instead of more extensively studied FAAH inhibitors. The commonly prescribed NSAID diclofenac sodium, a non-selective COX inhibitor, was used. It was hypothesized that coadministration of diclofenac 
SYNERGISTIC INHIBITION IN NEUROPATHIC PAIN

sodium and JZL184 enhances the analgesic effects of either compound, reducing mechanical and cold allodynia in the CCI mouse model of neuropathic pain.

\section{Statement of the Problem}

Neuropathic pain is a chronic ailment that decreases quality of life and correlates with psychological disorders such as depression and anxiety (Jensen et al., 2007; Sofaer-Bennett et al., 2007). Because neuropathic pain is particularly resistant to traditional analgesic treatments, including COX enzyme inhibitors commonly known as non-steroidal anti-inflammatory drugs (NSAIDs), patients often self-medicate with drugs of abuse, including Cannabis (Kogan \& Mechoulam, 2007). Traditional pain treatments including NSAIDs have negative and often severe side effects, there is a pressing need to identify new targets and treatments for neuropathic pain (Musumba et al., 2009). Current research focuses on the endogenous cannabinoid system, due to its ability to elicit behavioral and physiological modifications without apparent psychogenic side effects (Schlosburg, Kinsey, \& Lichtman, 2009). Highly selective endocannabinoid (eCB) enzyme inhibitors, which increase levels of eCBs in the brain and other target tissues, attenuate hyperalgesia and allodynia caused by nerve injury (Kinsey et al., 2009; Sasso et al., 2012).

Published reports support new therapeutic treatments that target both cyclooxygenase and endocannabinoid metabolic enzymes. Synergy allows for the use of subclinical doses of each compound, causing fewer side effects while maintaining analgesia (Guindon et al., 2007; Raffa, 2001). In addition, dual administration of an endocannabinoid enzyme inhibitor and an NSAID synergistically reduce acute visceral and local pain (Guindon \& Beaulieu, 2006; Naidu et al., 2009).

To date, investigations of synergy between the endocannabinoid enzyme inhibitors and COX inhibitors (i.e., NSAIDs) have focused entirely on fatty acid amide hydrolase (FAAH). Thus, the NSAID diclofenac sodium and an eCB enzyme monoacylglycerol lipase (MAGL) inhibitor were used to evaluate possible synergistic interactions in a neuropathic pain model.

\section{Methods}

Animals. Subjects consisted of 40 male C57BL/6J mice (Jackson Laboratory, Bar Harbor, ME) that were approximately 20 weeks old at the start of the experiment. Mice were housed 2-5 per cage in a temperature $\left(20-22^{\circ} \mathrm{C}\right)$ and humidity controlled environment with ad 
SYNERGISTIC INHIBITION IN NEUROPATHIC PAIN

libitum access to food and water. The Animal Care and Use Committee at West Virginia University approved all experimental protocols (11-0903).

Chronic constriction injury (CCI). Surgery was performed as described previously (Kinsey et al., 2009). Briefly, mice were anesthetized with inhaled isoflurane (Phoenix Pharmaceuticals, Burlingame, CA) with oxygen. The right hind leg was shaved and cleaned with three alternating wipes of Betadine solution, followed by ethanol. An incision was made on the skin of the posterior femur. After separating the muscle, the sciatic nerve was isolated and partially ligated with one 5-0 silk suture that was knotted 4 times. The muscle and skin were then closed with 6-0 nylon sutures. Mice recovered in clean, heated cages and were observed for absence of ataxia before being returned to the vivarium. Mice were administered the NSAID ketoprofen for three days, as a postoperative analgesic.

Behavior assessments. The mice were tested for allodynia, starting one week after surgery. Mice were tested once a week with a total of 15 testing days. On testing days the mice were brought into the testing room, weighed, injected, then placed inside ventilated polycarbonate chambers on an aluminum mesh table and allowed to acclimate for 60 min before testing. Mice were randomly assigned to drug treatment groups. Mice were injected with diclofenac sodium or vehicle 60 min before testing. For experiments using JZL184 alone and in combination with diclofenac, mice were injected with the drug treatment or vehicle 120 min before testing (Long et al., 2009). The injured paw of the vehicle treated mice acted as the control. The ipsilateral paw responses from the drug treatment groups were compared to the ipsilateral vehicle paw responses. The experimenter was blinded to all treatment groups.

Mechanical allodynia. Mechanical allodynia was tested using von Frey filaments (North Coast Medical, Morgan Hill, CA) using the “up-down” method (Chaplan, Pogrel, \& Yaksh, 1994; Kinsey et al., 2009). The plantar surface of each hind paw was stimulated with each filament, ranging from $0.16-6.0 \mathrm{~g}$, starting with the $0.6 \mathrm{~g}$ filament, five times at a frequency of $\sim 2 \mathrm{~Hz}$, (i.e., 2 stimulations per second). The filaments were tested in ascending order until the mouse lifted its paw after three out of the five stimulations (this was considered to be a positive response). Once a positive response occurred, the filaments were tested in descending order until a positive response was not detected, thus establishing a sensory threshold.

Acetone-induced cold allodynia. Approximately 30 min after the von Frey test, $10 \mu \mathrm{l}$ of acetone (99\% high-performance liquid chromatography grade; Thermo Fisher Scientific, 
SYNERGISTIC INHIBITION IN NEUROPATHIC PAIN

Waltham, MA) was propelled via a pipette (USA Scientific, Ocala, FL) onto the plantar surface of each hind paw to test cold allodynia (Choi, Yoon, Na, Kim, \& Chung, 1994; Decosterd \& Woolf, 2000). Acetone was applied from below the testing table via air burst by “expressing” the pipette, thereby avoiding mechanical stimulation of the paw with the pipette tip. Total time lifting or clutching each hind paw was recorded with an arbitrary maximum cutoff time of $20 \mathrm{~s}$ (Decosterd \& Woolf, 2000).

Drugs. Diclofenac sodium was purchased from Sigma-Aldrich (St. Louis, MO). An ample stock of JZL184 for the experiments was generously provided on an ongoing basis by our collaborator, Dr. Anu Mahadevan (Organix, Inc., Woburn, MA). Drugs were dissolved in a vehicle consisting of ethanol, Cremaphor (Sigma-Aldrich, St. Louis, MO), and normal saline in a ratio of 1:1:18 (Pinto, Moura, Serrão, Martins, \& Vieira-Coelho, 2010). All solutions were warmed to room temperature and injected intraperitoneally at a volume of $10 \mu \mathrm{l} / \mathrm{g}$ body mass.

Experimental Plan. The first experiment established the dose-response curve for diclofenac sodium and replicated the published dose-response for JZL184 (Kinsey, Nomura, et al., 2011) to establish anti-allodynic potency action. Mice were injected intraperitoneally with vehicle, diclofenac $(1,10,30,50,75$, or $100 \mathrm{mg} / \mathrm{kg})$ or JZL184 (1, 4, 8, 16, or $40 \mathrm{mg} / \mathrm{kg})$, and then assessed for mechanical and cold allodynia.

In the second experiment, a dose-response curve was established for the coadministration of diclofenac sodium and JZL184. The $\mathrm{ED}_{50}$ values (effective dose at which pain is reduced by $50 \%$ ) were determined based on the anti-allodynic dose-response curve of each compound from the first experiment. The ratios of JZL184 and diclofenac sodium are 1:3, 1:1, and 3:1 of the ED $_{50}$ of each drug (Naidu et al., 2009). The JZL184 and diclofenac sodium solutions were equipotent in dose and were determined from the individual dose-responses. The data were analyzed for subadditive, additive, and synergistic effects using isobolographic analysis.

As the CCI manipulation is a model of chronic pain, it allows for the repeated testing of mice, following sufficient "wash-out” time (i.e., 7 days between tests). This allows for repeated testing with no habituation, minimizing the number of animals required to complete these experiments (Chaplan, Bach, Pogrel, Chung, \& Yaksh, 1994).

Inter-rater reliability. All data were collected by a single experimenter. However, prior to the start of the present study, inter-rater reliability was assessed with two investigators, one with extensive experience (A) and one with moderate experience (B) for the mechanical allodynia test 
SYNERGISTIC INHIBITION IN NEUROPATHIC PAIN

and the cold allodynia test. During the test sessions, the investigators independently assessed each behavior and recorded responses on separate data sheets for each animal. Data were analyzed for agreement between investigators using a correlation coefficient. The coefficients for the investigators were .97 in the mechanical allodynia test and .99 in the cold allodynia test (Table 1).

Statistical Analysis. The results of the dose response curves of JZL184, diclofenac, and the combination ratios are presented as means \pm S.E.M. Pre- vs. post-surgery paw sensitivity data were analyzed using a two-way mixed design ANOVA (time point as within subjects and paw as a between subjects variable) followed by Bonferroni post hoc tests. Dose-response data were analyzed using one-way ANOVA, followed by Dunnett's post hoc test.

The $\mathrm{ED}_{50}$ values were calculated using a standard linear regression analysis of the doseresponse curve for each drug or in combination. To determine synergistic, additive, or subadditive interactions, the theoretical additive $\mathrm{ED}_{50}$ value of the combined drugs were calculated from the individual dose-response curves. The combination is assumed to equal the sum of the effects of each drug.

For isobolographic analysis, the dose of diclofenac sodium required to produce a $50 \%$ effect was plotted on the abscissa (x axis) and the isoeffective dose of JZL184 was plotted on the ordinate (y axis). A straight line connecting the two points represents the theoretical additive effect of JZL184 and diclofenac sodium. The drugs are considered additive if the experimental data points and their confidence intervals lie on this line. If the points lie below this line then the interaction is synergistic. If the points lie above the line the interaction is subadditive (or antagonistic). The $\mathrm{ED}_{50}$ value of the dual administration was determined by linear regression, in which the two drugs were summed at each concentration. The statistical difference between the theoretical $\mathrm{ED}_{50}$ value and the experimental $\mathrm{ED}_{50}$ value was analyzed using a Fisher's exact test.

\section{Results}

CCI induces mechanical and cold allodynia

Mice were tested for allodynia before and one week after CCI surgery. As reported previously, a significant difference in mechanical $[\mathrm{F}(1,38)=93.36, \mathrm{p}<.01$; Figure 2] and cold $[F(1,38)=57.42, \mathrm{p}<.01]$ allodynia was observed after the CCI surgery. Post hoc analyses revealed that this interaction was driven by paws ipsilateral to the nerve injury. On the other hand, CCI had no effect on paws contralateral to the nerve injury (mechanical allodynia $\mathrm{p}=.35$, 
SYNERGISTIC INHIBITION IN NEUROPATHIC PAIN

cold allodynia $\mathrm{p}=.42$ ). The ipsilateral paws were also significantly different from contralateral paws (mechanical allodynia $\mathrm{p}<.01$; cold allodynia $\mathrm{p}<.01$ ) after the CCI surgery.

Either JZL184 or diclofenac sodium dose dependently attenuate allodynia

Both JZL184 and diclofenac sodium dose-dependently attenuated CCI-induced allodynia. Administration of the MAGL inhibitor JZL184 significantly reduced mechanical allodynia [F (5, $72)=9.00, \mathrm{p}<.01$; Figure 3A $]$ and cold allodynia $[\mathrm{F}(5,72)=27.52, \mathrm{p}<.01$; Figure 3B $]$. Post hoc analyses revealed that JZL184 significantly attenuated mechanical allodynia at $\geq 8 \mathrm{mg} / \mathrm{kg}$, and cold allodynia at $\geq 4 \mathrm{mg} / \mathrm{kg}$. Diclofenac sodium also attenuated mechanical allodynia [F $(6,102)=4.47, \mathrm{p}<.01$; Figure $3 \mathrm{C}]$ and cold allodynia $[\mathrm{F}(6,102)=5.12, \mathrm{p}<.01$; Figure 3D . Post hoc analyses revealed that diclofenac significantly attenuated mechanical allodynia at $\geq 50$ $\mathrm{mg} / \mathrm{kg}$, and cold allodynia at $\geq 75 \mathrm{mg} / \mathrm{kg}$. The ED 50 for JZL184 was $8.04 \mathrm{mg} / \mathrm{kg}$ (CL 95\% = $4.49-14.40 \mathrm{mg} / \mathrm{kg}$ ) for mechanical allodynia; and $4.13 \mathrm{mg} / \mathrm{kg}$ (CL 95\% = 3.07-5.56 mg/kg) for cold allodynia. The ED50 for diclofenac sodium was $76.31 \mathrm{mg} / \mathrm{kg}$ (CL 95\% = 24.30-239.65 $\mathrm{mg} / \mathrm{kg}$ ) for mechanical allodynia; and $53.50 \mathrm{mg} / \mathrm{kg}$ (CL 95\% = 21.47-133.31 mg/kg) for cold allodynia.

Augmented anti-allodynic effects of JZL184 and diclofenac sodium

Coadministration of JZL184 and diclofenac sodium, at low doses, was found to be synergistically antinociceptive in mechanical allodynia and additive in the cold allodynia test. Four or five doses of the two compounds were administered in ratios of 1:3, 1:1, or 3:1 parts of JZL184 and diclofenac. The doses for each of these ratios were determined based on the respective $\mathrm{ED}_{50}$ value of either compound. The experimentally derived $\mathrm{ED}_{50}$ values $\left(\mathrm{Z}_{\mathrm{mix}}\right)$ from the dose response curves of the ratios (Figure 4) were compared to the predicted additive $\mathrm{ED}_{50}$ values $\left(Z_{\text {add }}\right)$. If the $\mathrm{ED}_{50}$ values of the $\mathrm{Z}_{\text {mix }}$ are below those of $\mathrm{Z}_{\text {add }}$ and the confidence intervals (CI) do not overlap, then the interaction is considered synergistic. The $\mathrm{Z}_{\text {mix }}$ in each ratio in the mechanical allodynia test was significantly less than the $\mathrm{Z}_{\text {add }}$ without CI overlap, indicating that the interaction was synergistic (Table 2). The $\mathrm{Z}_{\text {mix }}$ in each ratio in the cold allodynia test was less than the $\mathrm{Z}_{\mathrm{add}}$, however there was some CI overlap, and thus the interaction is considered additive (Table 2).

The $\mathrm{Z}_{\mathrm{mix}}$ results from each ratio dose response were plotted on an isobologram and compared to the predicted values (i.e. theoretical line of additivity) based on the individual ED $_{50}$ values of either drug. Because the experimental points of the collective mechanical allodynia 
SYNERGISTIC INHIBITION IN NEUROPATHIC PAIN

tests lie significantly below the line of additivity, the interaction was synergistic (Figure 5A).

The experimental points of the collective cold allodynia tests do not differ significantly from the theoretical line of additivity, and thus the interaction was additive (Figure 5B).

\section{Discussion}

Traditional pain treatments for neuropathic pain offer inconsistent pain relief and can have serious side effects including abuse potential, cardiovascular damage, and gastric hemorrhages, among others. The goal of this study was to test the hypothesis that dual inhibition of MAGL and COX synergistically decreases nociceptive responses in mice subjected to chronic constriction injury in mice. First, the analgesic potency of the selective MAGL inhibitor, JZL184, was tested. The blockade of MAGL with JZL184 dose dependently reduced paw lifts associated with neuropathic pain, which is consistent with previous findings (e.g. Kinsey et al., 2009, 2013). MAGL inhibition results in elevated brain and spinal cord levels of 2-AG and results in analgesia through a $\mathrm{CB}_{1}$ mechanism of action (Long et al., 2009, Kinsey et al., 2009). MAGL inhibition also has anti-allodynic and anti-edematous properties in an acute inflammation model (Gosh et al., 2013). In the present study, the blockade of COX via diclofenac reduced paw lifts at high doses ( $\geq 50 \mathrm{mg} / \mathrm{kg}$ ), which is consistent with the literature. However, previous research has found diclofenac to be effective at doses as low as $30 \mathrm{mg} / \mathrm{kg}$, with the full effect of COX inhibition being at higher doses (Botting, 2003; Takasaki et al., 2000).

Administration of multiple compounds, especially those in different classes, can increase analgesic efficacy while also reducing adverse side effects. Combining different drugs into an effective monotherapy can also simplify prescriptions and increase patient drug compliance (Raffa, 2001). Dual administration of a FAAH inhibitor and COX inhibitor synergistically reduces visceral pain, acute inflammation, and thermal and mechanical hyperalgesia in mice (Naidu et al., 2009; Sasso et al., 2012). In the present study, dual administration of a MAGL inhibitor and a COX inhibitor reduced mechanical and cold allodynia in a model of neuropathic pain. Using an isobolographic analysis, a synergistic interaction between diclofenac and JZL184 was found in the mechanical allodynia test and an additive interaction was found in the cold allodynia test. Thus, dual inhibition of COX and MAGL reduces the dose of either drug to the extent that significant reductions in allodynia were achieved at subthreshold doses.

Though this study did not directly test the specific mechanism(s) of action of this interaction, researching the mechanism of this synergistic relationship would be valuable. 
SYNERGISTIC INHIBITION IN NEUROPATHIC PAIN

However, because MAGL inhibition decreases brain levels of free arachidonic acid (Nomura 2011) and COX inhibition decreases free arachidonic acid from being converted into prostaglandins, it is plausible to speculate that both compounds may be working in concert to alter prostaglandin levels. Alternatively, a possible mechanism for the observed synergistic and additive interactions is that NSAIDs inhibit COX, thereby decreasing the biosynthesis of prostaglandins resulting in analgesia (Vane, 1971), while MAGL inhibition increases levels of 2AG acting on $\mathrm{CB}_{1}$ receptors resulting in analgesia (Long et al., 2009). Combining these two drugs leads to simultaneous reduction of prostaglandin synthesis and activation of $\mathrm{CB}_{1}$ receptors. Finally, some NSAIDs can inhibit FAAH when given in very high doses, thereby increasing anandamide brain levels (Holt et al., 2007). However, low doses do not seem to have this same effect.

Selective COX-2 inhibitors were developed to circumvent the detrimental gastrointestinal side effects of COX-1 inhibition, however patients using these drugs had a significant increase of negative cardiovascular events. These results lead to most coxibs, such as Vioxx, being removed from the market. Non-selective COX inhibitors (i.e. NSAIDs) also have an increased risk of a cardiovascular event. Cardiovascular risk can increase within a week of treatment initiation, especially with higher doses (Ong, Ong, Tan, \& Chean, 2013). The risk of cardiovascular event doubled for some NSAIDs at higher doses, while lower doses were nearly risk free for certain NSAIDs (McGettigan \& Henry, 2011). These findings support pain treatment using lower doses of NSAIDs to avoid adverse side effects.

Inhibition of either FAAH or MAGL prevents the gastrointestinal side effects of highdose NSAID administration (Kinsey, Nomura, et al., 2011; Naidu et al., 2009; Sasso et al., 2012). The interaction of dual administration of an NSAID and a MAGL inhibitor may further diminish unwanted NSAID side effects. It is noteworthy that the gastroprotective effects of MAGL inhibition were not replicated by exogenous administration of the endocannabinoid 2AG, presumably due to its rapid enzymatic regulation in vivo by MAGL, as detailed above (Kinsey, Nomura, et al., 2011).

Although there are many benefits to endocannabinoid modulation, repeated administration of high dose JZL184 ( $\geq 16 \mathrm{mg} / \mathrm{kg}$ ) causes downregulation and desensitization of $\mathrm{CB}_{1}$ receptors. This results in a reversal of the anti-nociceptive and gastroprotective effects of JZL184. However, repeated administration of low dose JZL184 (e.g., $\leq 8 \mathrm{mg} / \mathrm{kg}$ ) did not alter 
SYNERGISTIC INHIBITION IN NEUROPATHIC PAIN

receptor expression or function (Kinsey et al., 2013). In other words, at lower doses, repeated administration of JZL184 maintained previously reported analgesic and gastroprotective effects (Kinsey et al., 2013). These results support a potential therapeutic treatment of neuropathic pain with low dose endocannabinoid enzyme inhibitors similar to JZL184.

The ultimate goal of this research is to help identify targets for future pharmacological therapeutic treatments for patients experiencing neuropathic pain. Thus, a possible future direction is to examine the effectiveness of a monotherapy using a MAGL inhibitor in clinical trials in humans. Then, trials using dual administration of an NSAID and a MAGL inhibitor may be feasible. Although MAGL inhibition has not been tested in humans, a recent clinical trial tested a FAAH inhibitor in osteoarthritis patients for pain relief. While the drug did inhibit FAAH activity in the patients, it was indistinguishable from placebo in regard to analgesia (Huggins, Smart, Langman, Taylor, \& Young, 2012). Huggins et al. (2012) speculate that COX inhibition may also be needed for pain relief in humans. Considering the negative side effects of COX inhibition via high dose NSAIDs (e.g. gastrointestinal ulcers, cardiovascular, and renal failure), using a low dose of an NSAID may be ideal, however the lower dose alone might not be sufficient for analgesia.

More than 12 million people in the United States use prescription drugs non-medically ("Policy impact: Prescription," 2013). This problem is especially rampant in the Appalachian region. West Virginia has the highest per capita overdose mortality rates in the country and 90\% of these deaths are due to prescription drugs like oxycodone and methadone (Booth \& Kerlikowske, 2001). West Virginia also experienced the biggest increase in unintentional drug poisoning death rates in the United States (Hall, Hawkinberry, \& Moyers-Scott, 2010). Opioid abuse was the main reason for these deaths, though combining these drugs with alcohol was a major contributing factor. The direct costs to West Virginia rose to \$1.86 billion in 2006 alone (Hall et al., 2010). Opioid addiction in West Virginia has reached national attention with the recent documentary “Oxyana,” which details the extensive oxycodone abuse problem in Oceana, West Virginia. Methadone is another abused opioid that causes death more in patients taking the prescription for pain relief than those taking methadone for opiate addiction therapy (Paulozzi, Budnitz, \& Xi, 2006). Physicians started prescribing methadone as a pain treatment due to its lower cost, however the high abuse potential and the depressant effects were initially underestimated. Recreational use of methadone has increased in recent years. Deaths due to 
SYNERGISTIC INHIBITION IN NEUROPATHIC PAIN

methadone in West Virginian were significantly higher in younger age groups than deaths due to other opioids (Paulozzi et al., 2009). Thus, there is a critical need for new approaches to pain reduction that have a reduced risk of abuse. Avoiding opioids and other pain treatments that have high abuse potential would be beneficial to society and for the patient. Endocannabinoid modulators and NSAIDs both have low abuse liability, which suggests that FAAH or MAGL inhibitors may indeed make for good treatment options. Dual administration of these drugs along with an NSAID may further reduce abuse liability.

New pain treatments are also needed because the gastrointestinal side effects of NSAIDs can be life threatening, especially in elderly patients. Chronic NSAID use in elderly patients has an increased chance of adverse side effects such as a cardiovascular event and gastric hemorrhages (Arneric, Laird, Chappell, \& Kennedy, 2013; Ong et al., 2013). Older people are among the highest users of analgesic medications (Arneric et al., 2013), however there has not been sufficient research to determine the safest treatment options for these patients. For example, there have been few clinical trials specifically investigating elderly patients, due to cognitive and health exclusion criteria. However the co-morbidities that are associated with the elderly may have an impact on the efficacy and safety of these analgesics (Arneric et al., 2013) If pain is not managed effectively it can lead to loss of mobility, physical function, and a decrease in the quality of life for older patients.

Possible future directions of this research include testing dual administration of the MAGL inhibitor and an NSAID in other models of pain, such as inflammatory or postsurgical hyperalgesia. Because dual administration of these two classes of drugs yield significant analgesic potency at low doses, this strategy may not just be limited to neuropathic pain but may instead be used effectively in a myriad of ailments. For example, as mentioned above, dual FAAH/COX inhibition reduces acute visceral pain (Naidu et al., 2009), although MAGL inhibitors have not been tested in this paradigm. Similarly, although it has been reported previously that chronic low dose JZL184 does not cause functional CB 1 receptor loss (Kinsey et al., 2013), it is possible that chronic dual administration could have unknown negative effects that may or may not be limited to $\mathrm{CB}_{1}$. Thus, a longer-term study in which JZL184 and diclofenac are administered repeatedly may be worth investigating.

One limitation of the present study is that it did not investigate the possible analgesic effects of JZL184 and/or diclofenac on spontaneous pain. Spontaneous pain, which includes 
SYNERGISTIC INHIBITION IN NEUROPATHIC PAIN

phantom limb pain, is a common type of chronic pain that results from neuropathy in humans. Unfortunately, there are no well-accepted preclinical animal models of spontaneous pain, and so interpretation of the present data is limited to neuropathic allodynia. That is, the analgesic effects of COX and MAGL inhibition may or may not effectively treat spontaneous pain. It may well be the case that little will be known about the analgesic efficacy of endocannabinoid modulation in spontaneous pain until clinical trials are conducted in neuropathic pain patients. While other types of chronic pain are more common, patients with neuropathic pain tend to report higher pain severity scores and an increase use of analgesics (Torrance, Smith, Bennett, \& Lee, 2006), again underscoring the need to develop new effective pain treatments.

In summary, coadministration of JZL184 and diclofenac sodium synergistically reduced CCI-induced mechanical allodynia and additively reduced cold allodynia in mice. The combined inhibition of MAGL and COX enzymes may be beneficial in maximizing analgesia while at the same time reducing NSAID side effects, in particular gastrointestinal ulcers. While this is an exciting outcome, MAGL inhibitors are not currently approved for use in humans, and thus clinical trials are still needed to test the efficacy of these drugs. In addition, further research is needed to elucidate the specific physiological mechanisms by which the observed synergistic reduction in allodynia occurs. 
SYNERGISTIC INHIBITION IN NEUROPATHIC PAIN

References

Ahn, K., McKinney, M. K., \& Cravatt, B. F. (2008). Enzymatic pathways that regulate endocannabinoid signaling in the nervous system. Chem Rev, 108(5), 1687-1707. doi:10.1021/cr0782067

Arneric, S. P., Laird, J. M. A., Chappell, A. S., \& Kennedy, J. D. (2013). Tailoring chronic pain treatments for the elderly: Are we prepared for the challenge? Drug discovery today. doi:10.1016/j.drudis.2013.08.017

Attal, N., Cruccu, G., Haanpaa, M., Hansson, P., Jensen, T. S., Nurmikko, T., ... Wiffen, P. (2006). EFNS guidelines on pharmacological treatment of neuropathic pain. Eur J Neurol, 13(11), 1153-1169. doi:10.1111/j.1468-1331.2006.01511.x

Beal, B., Moeller-Bertram, T., Schilling, J. M., \& Wallace, M. S. (2012). Gabapentin for oncedaily treatment of post-herpetic neuralgia: a review. Clin Interv Aging, 7, 249-255. doi:10.2147/CIA.S23783

Botting, R. (2003). COX-1 and COX-3 inhibitors. Thrombosis research, 110(5-6), 269-72. Retrieved from http://www.ncbi.nlm.nih.gov/pubmed/14592546

Braden, J. B., \& Sullivan, M. D. (2008). Suicidal thoughts and behavior among adults with selfreported pain conditions in the national comorbidity survey replication. J Pain, 9(12), 1106-1115. doi:10.1016/j.jpain.2008.06.004

Chaplan, S. R., Bach, F. W., Pogrel, J. W., Chung, J. M., \& Yaksh, T. L. (1994). Quantitative assessment of tactile allodynia in the rat paw. J Neurosci Methods, 53(1), 55-63. Retrieved from http://www.ncbi.nlm.nih.gov/pubmed/7990513

Chaplan, S. R., Pogrel, J. W., \& Yaksh, T. L. (1994). Role of voltage-dependent calcium channel subtypes in experimental tactile allodynia. J Pharmacol Exp Ther, 269(3), 1117-1123. Retrieved from http://www.ncbi.nlm.nih.gov/pubmed/8014856

Choi, Y., Yoon, Y. W., Na, H. S., Kim, S. H., \& Chung, J. M. (1994). Behavioral signs of ongoing pain and cold allodynia in a rat model of neuropathic pain. Pain, 59(3), 369-376. Retrieved from http://www.ncbi.nlm.nih.gov/pubmed/7708411

Decosterd, I., \& Woolf, C. J. (2000). Spared nerve injury: an animal model of persistent peripheral neuropathic pain. Pain, 87(2), 149-158. Retrieved from http://www.ncbi.nlm.nih.gov/pubmed/10924808

Eisenberg, E., McNicol, E., \& Carr, D. B. (2006). Opioids for neuropathic pain. Cochrane Database Syst Rev, (3), CD006146. doi:10.1002/14651858.CD006146 


\section{SYNERGISTIC INHIBITION IN NEUROPATHIC PAIN}

FitzGerald, G. A., \& Patrono, C. (2001). The coxibs, selective inhibitors of cyclooxygenase-2. $N$ Engl J Med, 345(6), 433-442. doi:10.1056/NEJM200108093450607

Gaoni, Y., \& Mechoulam, R. (1964). Isolation, Structure, and Partial Synthesis of an Active Constituent of Hashish'. Journal of the American Chemical Society, 86, 1646-1647. Retrieved from http://cbdcrew.org/assets/cbd-Mechoulam-1964.pdf

Gosh, S., Wise, L. E., Chen, Y., Gujjar, R., Mahadevan, A., Cravatt, B. F., \& Lichtman, A. H. (2013). The monoacylglycerol lipase inhibitor JZL184 suppresses inflammatory pain in the mouse carrageenan model. Life Sciences. doi:10.1016/j.lfs.2012.06.020

Guindon, J., \& Beaulieu, P. (2006). Antihyperalgesic effects of local injections of anandamide, ibuprofen, rofecoxib and their combinations in a model of neuropathic pain.

Neuropharmacology, 50(7), 814-823. doi:10.1016/j.neuropharm.2005.12.002

Guindon, J., Walczak, J. S., \& Beaulieu, P. (2007). Recent advances in the pharmacological management of pain. Drugs, 67(15), 2121-2133. Retrieved from http://www.ncbi.nlm.nih.gov/pubmed/17927280

Hall, P. B., Hawkinberry, D., \& Moyers-Scott, P. (2010). Prescription drug abuse \& addiction: past, present and future: the paradigm for an epidemic. The West Virginia medical journal, 106(4 Spec No), 26-32. Retrieved from http://www.ncbi.nlm.nih.gov/pubmed/21932750

Herkenham, M., Lynn, A. B., Johnson, M. R., Melvin, L. S., de Costa, B. R., \& Rice, K. C. (1991). Characterization and localization of cannabinoid receptors in rat brain: a quantitative in vitro autoradiographic study. J Neurosci, 11(2), 563-583. Retrieved from http://www.ncbi.nlm.nih.gov/pubmed/1992016

Holt, S., Paylor, B., Boldrup, L., Alajakku, K., Vandevoorde, S., Sundström, A., ... Fowler, C. J. (2007). Inhibition of fatty acid amide hydrolase, a key endocannabinoid metabolizing enzyme, by analogues of ibuprofen and indomethacin. European Journal of Pharmacology, 565(1-3), 26-36. doi:10.1016/j.ejphar.2007.02.051

Huggins, J. P., Smart, T. S., Langman, S., Taylor, L., \& Young, T. (2012). An efficient randomised, placebo-controlled clinical trial with the irreversible fatty acid amide hydrolase-1 inhibitor PF-04457845, which modulates endocannabinoids but fails to induce effective analgesia in patients with pain due to osteoarthritis of th. Pain, 153, 1837-1846. Retrieved from http://www.sciencedirect.com.www.libproxy.wvu.edu/science/article/pii/S03043959120026 92\#

Jensen, M. P., Chodroff, M. J., \& Dworkin, R. H. (2007). The impact of neuropathic pain on health-related quality of life: review and implications. Neurology, 68(15), 1178-1182. doi:10.1212/01.wnl.0000259085.61898.9e 
SYNERGISTIC INHIBITION IN NEUROPATHIC PAIN

Justinova, Z., Mangieri, R. A., Bortolato, M., Chefer, S. I., Mukhin, A. G., Clapper, J. R., ... Goldberg, S. R. (2008). Fatty acid amide hydrolase inhibition heightens anandamide signaling without producing reinforcing effects in primates. Biol Psychiatry, 64(11), 930937. doi:10.1016/j.biopsych.2008.08.008

Kinsey, Long, J. Z., O’Neal, S. T., Abdullah, R. A., Poklis, J. L., Boger, D. L., ... Lichtman, A. H. (2009). Blockade of endocannabinoid-degrading enzymes attenuates neuropathic pain. The Journal of pharmacology and experimental therapeutics, 330(3), 902-10. doi:10.1124/jpet.109.155465

Kinsey, Nomura, D., O’Neal, S., Long, J., Mahadevan, A., Cravatt, B., ... Lichtman, A. (2011). Inhibition of monoacylglycerol lipase attenuates nonsteroidal anti-inflammatory druginduced gastric hemorrhages in mice. J Pharmacol Exp Ther, 338(3), 795-802. doi:10.1124/jpet.110.175778

Kinsey, S G, O’Neal, S. T., Long, J. Z., Cravatt, B. F., \& Lichtman, A. H. (2011). Inhibition of endocannabinoid catabolic enzymes elicits anxiolytic-like effects in the marble burying assay. Pharmacol Biochem Behav, 98(1), 21-27. doi:10.1016/j.pbb.2010.12.002

Kinsey, Steven G, Wise, L. E., Ramesh, D., Abdullah, R., Selley, D. E., Cravatt, B. F., \& Lichtman, A. H. (2013). Repeated low-dose administration of the monoacylglycerol lipase inhibitor JZL184 retains cannabinoid receptor type 1-mediated antinociceptive and gastroprotective effects. The Journal of pharmacology and experimental therapeutics, 345(3), 492-501. doi:10.1124/jpet.112.201426

Kogan, N. M., \& Mechoulam, R. (2007). Cannabinoids in health and disease. Dialogues Clin Neurosci, 9(4), 413-430. Retrieved from http://www.ncbi.nlm.nih.gov/pubmed/18286801

Krueger, A. B., \& Stone, A. A. (2008). Assessment of pain: a community-based diary survey in the USA. Lancet, 371(9623), 1519-1525. doi:10.1016/S0140-6736(08)60656-X

La Rana, G., Russo, R., D’Agostino, G., Sasso, O., Raso, G. M., Iacono, A., ... Calignano, A. (2008). AM404, an anandamide transport inhibitor, reduces plasma extravasation in a model of neuropathic pain in rat: role for cannabinoid receptors. Neuropharmacology, 54(3), 521529. doi:10.1016/j.neuropharm.2007.10.021

Lambert, D. M., DiPaolo, F. G., Sonveaux, P., Kanyonyo, M., Govaerts, S. J., Hermans, E., ... Tschirhart, E. J. (1999). Analogues and homologues of N-palmitoylethanolamide, a putative endogenous $\mathrm{CB}(2)$ cannabinoid, as potential ligands for the cannabinoid receptors.

Biochimica et biophysica acta, 1440(2-3), 266-74. Retrieved from http://www.ncbi.nlm.nih.gov/pubmed/10521710

Lanas, A. (2009). Nonsteroidal antiinflammatory drugs and cyclooxygenase inhibition in the gastrointestinal tract: a trip from peptic ulcer to colon cancer. Am J Med Sci, 338(2), 96106. doi:10.1097/MAJ.0b013e3181ad8cd3 
SYNERGISTIC INHIBITION IN NEUROPATHIC PAIN

Lichtman, A. H., Blankman, J. L., \& Cravatt, B. F. (2010). Endocannabinoid overload. Mol Pharmacol, 78(6), 993-995. doi:10.1124/mol.110.069427

Lichtman, A. H., Shelton, C. C., Advani, T., \& Cravatt, B. F. (2004). Mice lacking fatty acid amide hydrolase exhibit a cannabinoid receptor-mediated phenotypic hypoalgesia. Pain, 109(3), 319-327. doi:10.1016/j.pain.2004.01.022

Lim, G., Sung, B., Ji, R. R., \& Mao, J. (2003). Upregulation of spinal cannabinoid-1-receptors following nerve injury enhances the effects of Win 55,212-2 on neuropathic pain behaviors in rats. Pain, 105(1-2), 275-283. Retrieved from http://www.ncbi.nlm.nih.gov/pubmed/14499445

Long, J. Z., Li, W., Booker, L., Burston, J. J., Kinsey, S. G., Schlosburg, J. E., ... Cravatt, B. F. (2009). Selective blockade of 2-arachidonoylglycerol hydrolysis produces cannabinoid behavioral effects. Nat Chem Biol, 5(1), 37-44. doi:10.1038/nchembio.129

McGettigan, P., \& Henry, D. (2011). Cardiovascular risk with non-steroidal anti-inflammatory drugs: systematic review of population-based controlled observational studies. PLoS medicine, 8(9), e1001098. doi:10.1371/journal.pmed.1001098

McMahon, S. B., Cafferty, W. B., \& Marchand, F. (2005). Immune and glial cell factors as pain mediators and modulators. Exp Neurol, 192(2), 444-462. doi:10.1016/j.expneurol.2004.11.001

Mechoulam, R., \& Parker, L. A. (2012). The Endocannabinoid System and the Brain. Annu Rev Psychol. doi:10.1146/annurev-psych-113011-143739

Musumba, C., Pritchard, D. M., \& Pirmohamed, M. (2009). Review article: cellular and molecular mechanisms of NSAID-induced peptic ulcers. Aliment Pharmacol Ther, 30(6), 517-531. doi:10.1111/j.1365-2036.2009.04086.x

Naidu, P. S., Booker, L., Cravatt, B. F., \& Lichtman, A. H. (2009). Synergy between enzyme inhibitors of fatty acid amide hydrolase and cyclooxygenase in visceral nociception. $J$ Pharmacol Exp Ther, 329(1), 48-56. doi:10.1124/jpet.108.143487

Nomura, D. K., Morrison, B. E., Blankman, J. L., Long, J. Z., Kinsey, S. G., Marcondes, M. C., ... Cravatt, B. F. (2011). Endocannabinoid hydrolysis generates brain prostaglandins that promote neuroinflammation. Science, 334(6057), 809-813. doi:10.1126/science.1209200

Ong, H. T., Ong, L. M., Tan, T. E., \& Chean, K. Y. (2013). Cardiovascular effects of common analgesics. The Medical journal of Malaysia, 68, 189-94.

Patrono, C., \& Baigent, C. (2009). Low-dose aspirin, coxibs, and other NSAIDS: a clinical mosaic emerges. Mol Interv, 9(1), 31-39. doi:10.1124/mi.9.1.8 
SYNERGISTIC INHIBITION IN NEUROPATHIC PAIN

Paulozzi, L. J., Budnitz, D. S., \& Xi, Y. (2006). Increasing deaths from opioid analgesics in the United States. Pharmacoepidemiology and drug safety, 15(9), 618-27.

doi:10.1002/pds.1276

Paulozzi, L. J., Logan, J. E., Hall, A. J., McKinstry, E., Kaplan, J. A., \& Crosby, A. E. (2009). A comparison of drug overdose deaths involving methadone and other opioid analgesics in West Virginia. Addiction (Abingdon, England), 104(9), 1541-8. doi:10.1111/j.13600443.2009.02650.x

Pinto, C. E., Moura, E., Serrão, M. P., Martins, M. J., \& Vieira-Coelho, M. A. (2010). Effect of (-)-Delta(9)-tetrahydrocannabinoid on the hepatic redox state of mice. Brazilian journal of medical and biological research = Revista brasileira de pesquisas médicas e biológicas / Sociedade Brasileira de Biofísica ... [et al.], 43(4), 325-9. doi:10.1590/S0100879X2010007500015

Raffa, R. B. (2001). Pharmacology of oral combination analgesics: rational therapy for pain. $J$ Clin Pharm Ther, 26(4), 257-264. Retrieved from http://www.ncbi.nlm.nih.gov/pubmed/11493367

Rahn, E. J., \& Hohmann, A. G. (2009). Cannabinoids as pharmacotherapies for neuropathic pain: from the bench to the bedside. Neurotherapeutics, 6(4), 713-737.

doi:10.1016/j.nurt.2009.08.002

Rouzer, C. A., \& Marnett, L. J. (2009). Cyclooxygenases: structural and functional insights. J Lipid Res, 50 Suppl, S29-34. doi:10.1194/jlr.R800042-JLR200

Russo, R., Loverme, J., La Rana, G., Compton, T. R., Parrott, J., Duranti, A., ... Piomelli, D. (2007). The fatty acid amide hydrolase inhibitor URB597 (cyclohexylcarbamic acid 3'carbamoylbiphenyl-3-yl ester) reduces neuropathic pain after oral administration in mice. $J$ Pharmacol Exp Ther, 322(1), 236-242. doi:10.1124/jpet.107.119941

Sasso, O., Bertorelli, R., Bandiera, T., Scarpelli, R., Colombano, G., Armirotti, A., ... Piomelli, D. (2012). Peripheral FAAH inhibition causes profound antinociception and protects against indomethacin-induced gastric lesions. Pharmacol Res, 65(5), 553-563.

doi:10.1016/j.phrs.2012.02.012

Schlosburg, J. E., Kinsey, S. G., \& Lichtman, A. H. (2009). Targeting fatty acid amide hydrolase (FAAH) to treat pain and inflammation. AAPS J, 11(1), 39-44. doi:10.1208/s12248-0089075-y

Scholz, J., \& Woolf, C. J. (2002). Can we conquer pain? Nat Neurosci, 5 Suppl, 1062-1067. doi:10.1038/nn942

Sheskin, T., Hanus, L., Slager, J., Vogel, Z., \& Mechoulam, R. (1997). Structural requirements for binding of anandamide-type compounds to the brain cannabinoid receptor. Journal of medicinal chemistry, 40(5), 659-67. doi:10.1021/jm960752x 
SYNERGISTIC INHIBITION IN NEUROPATHIC PAIN

Singh, G. (1998). Recent considerations in nonsteroidal anti-inflammatory drug gastropathy. Am J Med, 105(1B), 31S-38S. Retrieved from http://www.ncbi.nlm.nih.gov/pubmed/9715832

Sofaer-Bennett, B., Walker, J., Moore, A., Lamberty, J., Thorp, T., \& O’Dwyer, J. (2007). The social consequences for older people of neuropathic pain: a qualitative study. Pain Med, 8(3), 263-270. doi:10.1111/j.1526-4637.2006.00222.x

Takasaki, I., Andoh, T., Nitta, M., Takahata, H., Nemoto, H., Shiraki, K., ... Kuraishi, Y. (2000). Pharmacological and immunohistochemical characterization of a mouse model of acute herpetic pain. Japanese journal of pharmacology, 83(4), 319-26. Retrieved from http://www.ncbi.nlm.nih.gov/pubmed/11001178

Tallarida, R. J. (2011). Quantitative methods for assessing drug synergism. Genes Cancer, 2(11), 1003-1008. doi:10.1177/1947601912440575

Torrance, N., Smith, B. H., Bennett, M. I., \& Lee, A. J. (2006). The epidemiology of chronic pain of predominantly neuropathic origin. Results from a general population survey. The journal of pain : official journal of the American Pain Society, 7(4), 281-9. doi:10.1016/j.jpain.2005.11.008

VANE, J. R. (1971). Inhibition of Prostaglandin Synthesis as a Mechanism of Action for Aspirin-like Drugs. Nature, 231(25), 232-235. doi:10.1038/10.1038/newbio231232a0

Viegas, A., Manso, J., Corvo, M. C., Marques, M. M., \& Cabrita, E. J. (2011). Binding of ibuprofen, ketorolac, and diclofenac to COX-1 and COX-2 studied by saturation transfer difference NMR. J Med Chem, 54(24), 8555-8562. doi:10.1021/jm201090k

Wise, L. E., Thorpe, A. J., \& Lichtman, A. H. (2009). Hippocampal CB(1) receptors mediate the memory impairing effects of Delta(9)-tetrahydrocannabinol. Neuropsychopharmacology, 34(9), 2072-2080. doi:10.1038/npp.2009.31

Woolridge, E., Barton, S., Samuel, J., Osorio, J., Dougherty, A., \& Holdcroft, A. (2005). Cannabis use in HIV for pain and other medical symptoms. J Pain Symptom Manage, 29(4), 358-367. doi:10.1016/j.jpainsymman.2004.07.011

Zimmermann, M. (2001). Pathobiology of neuropathic pain. Eur J Pharmacol, 429(1-3), 23-37. Retrieved from http://www.ncbi.nlm.nih.gov/pubmed/11698024

IOM (Institute of Medicine). (2011). Relieving Pain in America: A Blueprint for Transforming Prevention, Care, Education, and Research. Washington DC: The National Academies Press. 
SYNERGISTIC INHIBITION IN NEUROPATHIC PAIN 
SYNERGISTIC INHIBITION IN NEUROPATHIC PAIN

Table 1

P values for inter-observer correlation

Mechanical Allodynia Correlation

Investigator A Investigator B

\begin{tabular}{llll}
\hline Investigator A & Pearson Correlation & 1 & $.973^{* *}$ \\
& Sig. (2-tailed) & & .000 \\
& $\mathrm{~N}$ & 24 & 24 \\
Investigator B & Pearson Correlation & $.973^{* *}$ & 1 \\
& Sig. (2-tailed) & .000 & \\
& $\mathrm{~N}$ & 24 & 24 \\
\hline
\end{tabular}

\section{Cold Allodynia Correlation}

Investigator A Investigator B

\begin{tabular}{llll}
\hline Investigator A & Pearson Correlation & 1 & $.989 * *$ \\
& Sig. (2-tailed) & & .000 \\
& $\mathrm{~N}$ & 24 & 24 \\
Investigator B & Pearson Correlation & $.989^{* *}$ & 1 \\
& Sig. (2-tailed) & .000 & \\
& $\mathrm{~N}$ & 24 & 24 \\
\hline
\end{tabular}

** Correlation is significant at the .01 level (2-tailed)

Table 1. Prior to the start of the present study, inter-rater reliability was assessed with two investigators, one with extensive experience (A) and one with moderate experience (B) in testing using the "up-down" method in the mechanical allodynia test and using separate stop watches in the cold allodynia test. During the test sessions the investigators recorded responses on separate data sheets for each animal. Data were analyzed for agreement between investigators using Pearson correlation, $* * \mathrm{p}<.01$. 
SYNERGISTIC INHIBITION IN NEUROPATHIC PAIN

Table 2

$E D_{50}$ values of JZL184 and diclofenac sodium in combination

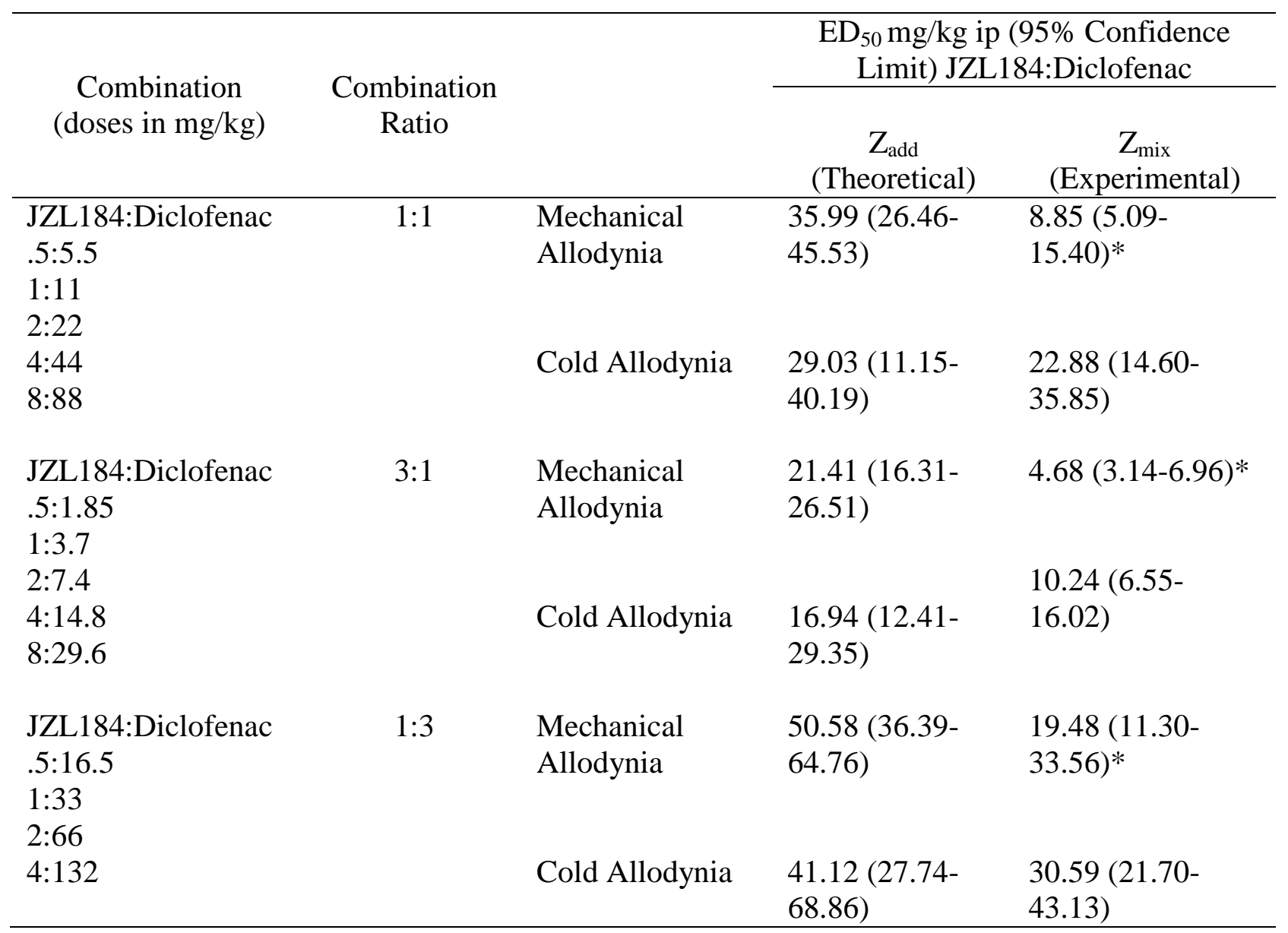

The $\mathrm{Z}_{\mathrm{add}}$ and $\mathrm{Z}_{\mathrm{mix}}$ values reflect the total amount of both drugs combined, where diclofenac and JZL184 were summed for each combination.

$* p<.05$ compared with $\mathrm{Z}_{\text {add }}$ using the Fisher test.

Experimentally determined $\mathrm{Z}_{\text {mix }}$ values and predicted $\mathrm{Z}_{\text {add }}$ values (95\% CL) for mixtures of JZL184 and diclofenac in assays of acetone and von Frey. Asterisks indicate a synergistic interaction as evidence of non-overlapping 95\% CL between $\mathrm{Z}_{\text {mix }}$ and $\mathrm{Z}_{\text {add }}$ values. 

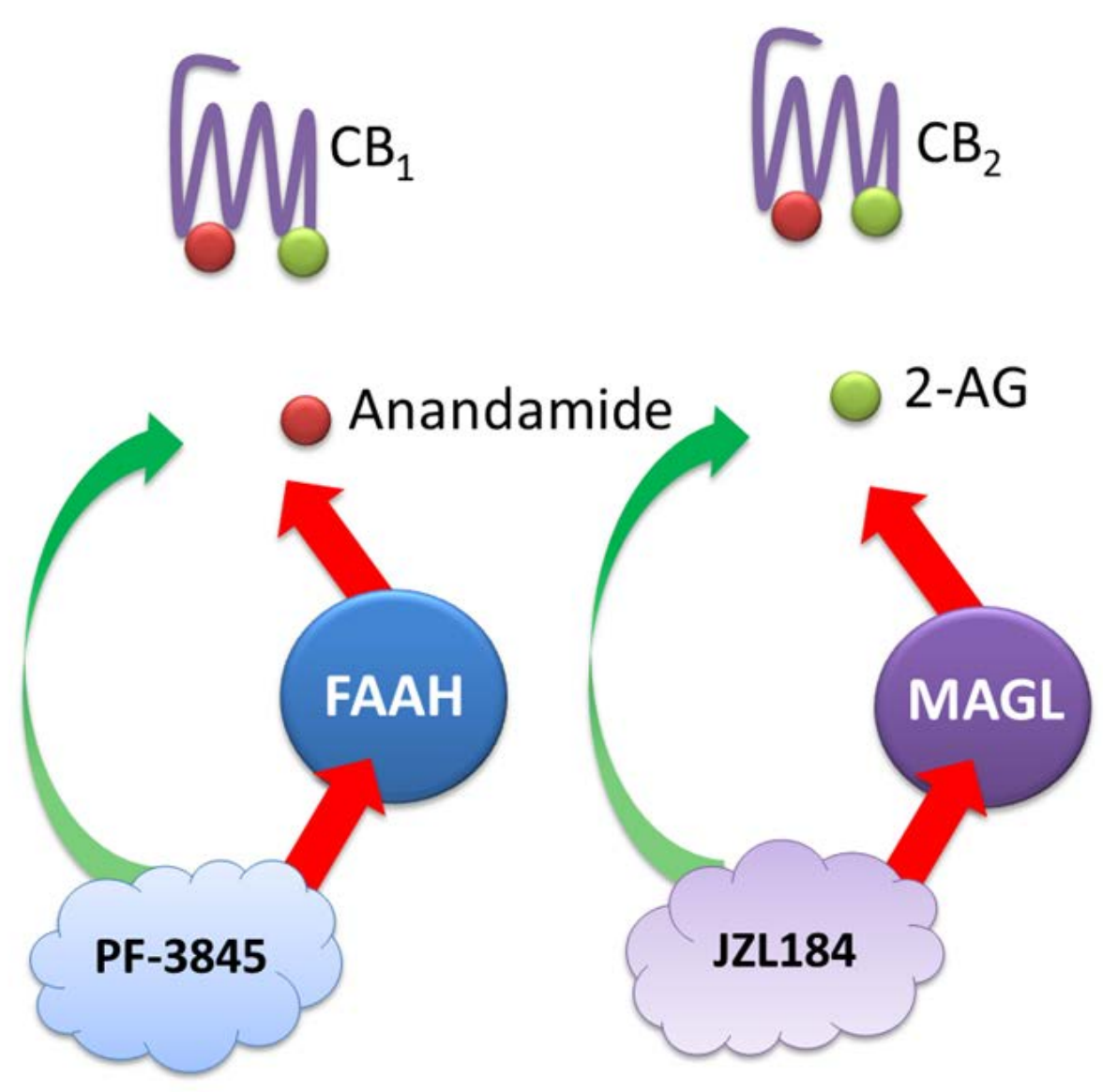

Figure 1. Schematic drawing of the endocannabinoid (eCB) system. The two eCB receptors bind the endocannabinoids anandamide and 2-AG. These endocannabinoids are tightly regulated by the metabolic enzymes fatty acid amide hydrolase (FAAH) and monoacylglycerol lipase (MAGL). Pharmacological inhibition of FAAH or MAGL causes an increase in physiological levels of the eCB that either enzyme metabolizes. For example, the compound JZL184 inhibits MAGL activity, which indirectly increases brain levels of the endocannabinoid 2-AG. Red arrows indicate decreased function, green arrow indicate increased function 

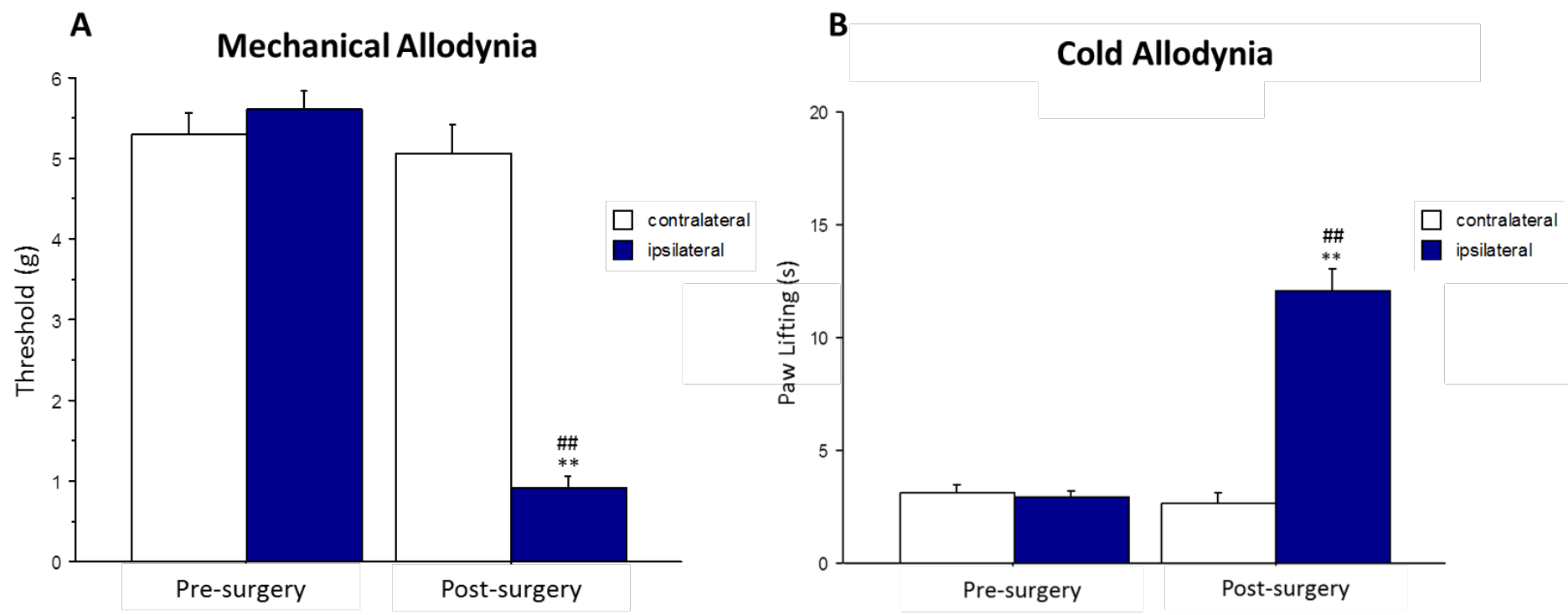

Figure 2. Chronic constriction injury causes mechanical and cold allodynia. Mice were tested for (A) mechanical and (B) cold allodynia prior to and one week following surgery. Data are expressed as mean $( \pm)$ SEM. $(n=20)$. ${ }^{* *} \mathrm{p}<.01$ versus contralateral paw, \#\# $\mathrm{p}<.01$ versus presurgery ipsilateral paw, Bonferroni post hoc. 
A

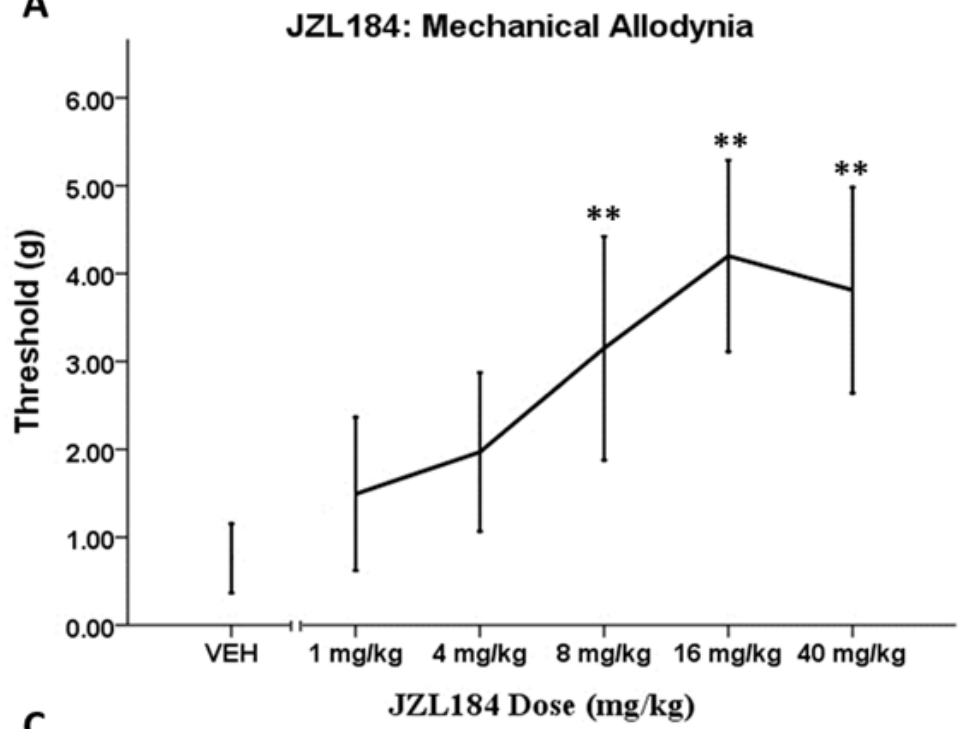

C

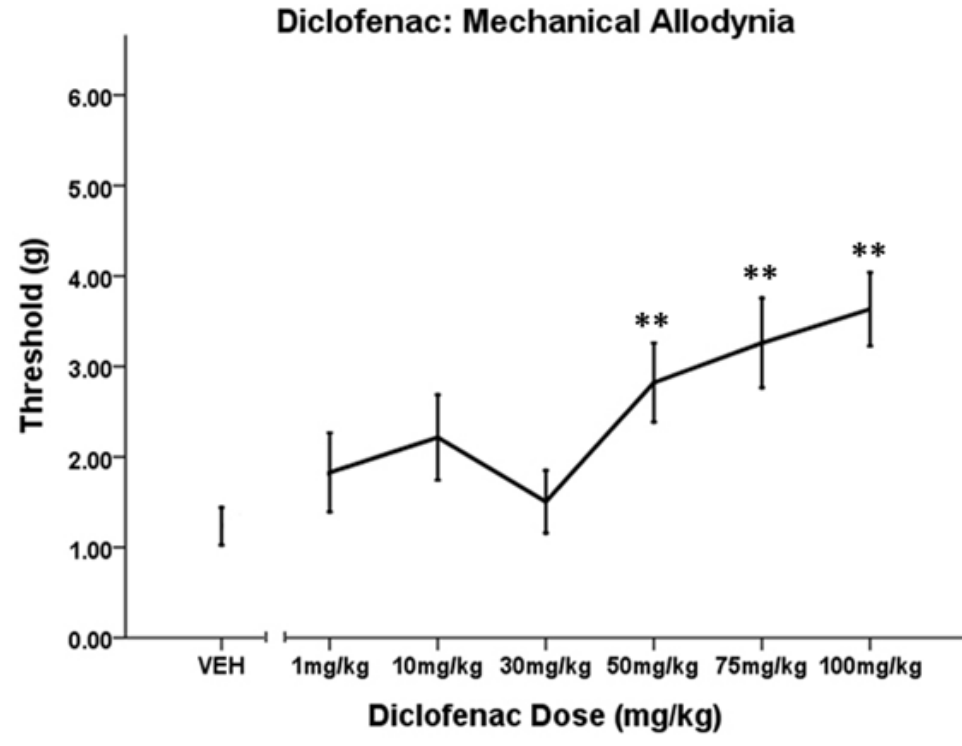

B
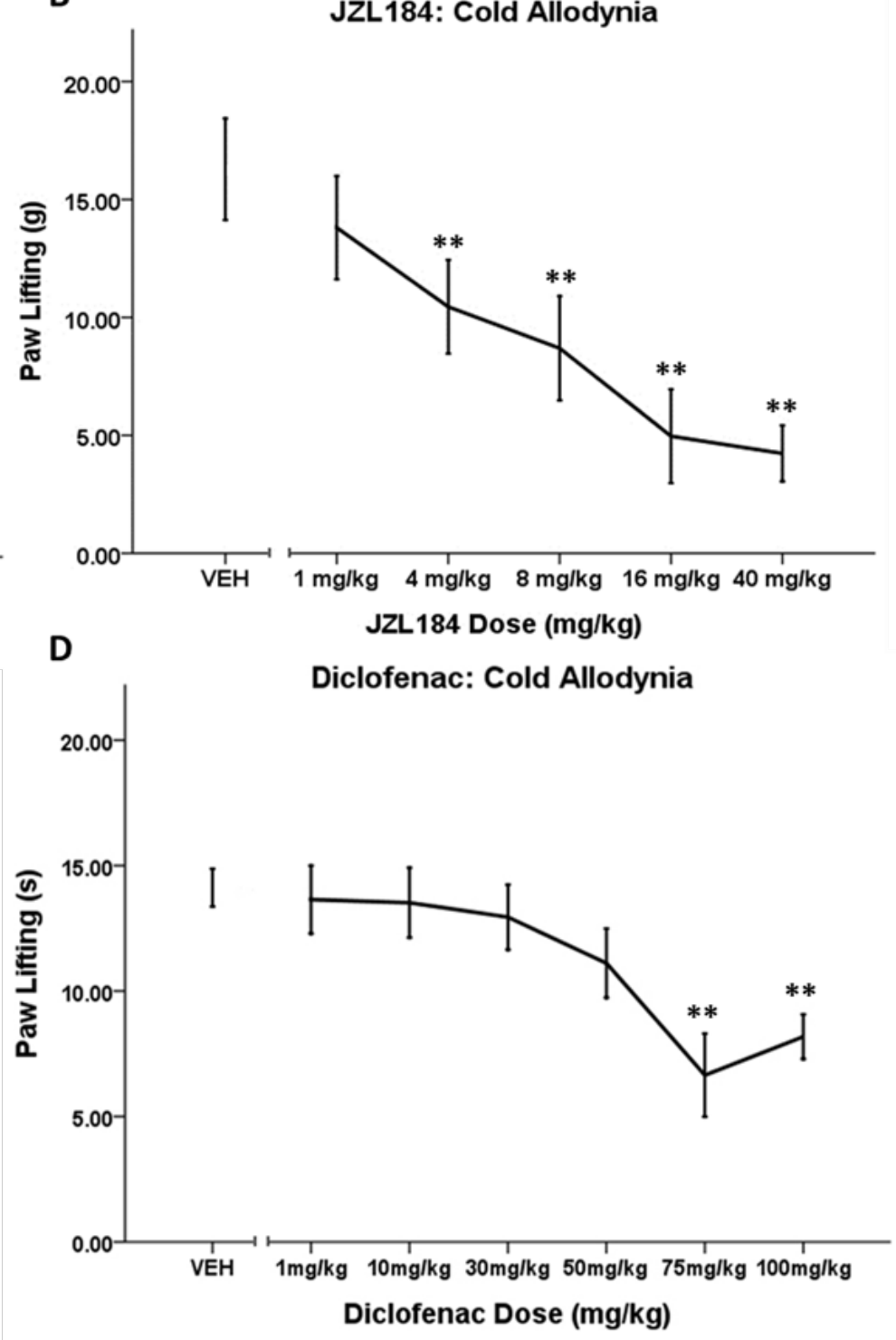

Figure 3. The MAGL inhibitor, JZL184, or the COX inhibitor, diclofenac sodium, dose-dependently attenuates mechanical and cold allodynia in the CCI model of neuropathic pain. Mice were subjected to CCI and then tested for mechanical (A, B) and acetone-induced cold allodynia (C, D). Data are expressed as mean ( \pm ) SEM. ( $\mathrm{n}=10-18) .{ }^{* *} \mathrm{p}<.01$ versus vehicle, Dunnett post hoc. 

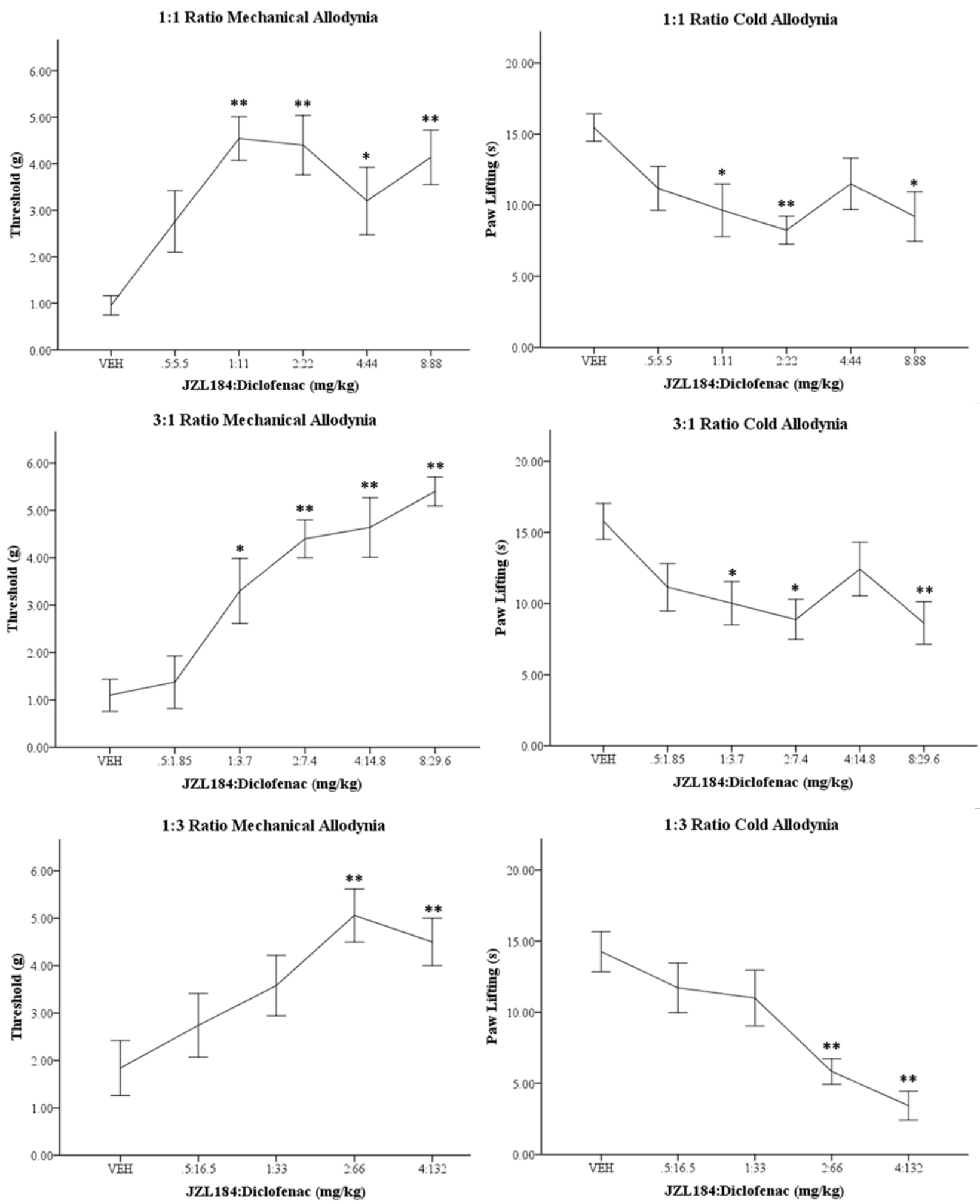

Figure 4. Dual administration of JZL184 and diclofenac attenuates mechanical and cold allodynia. Ratios of 1:1, 3:1, and 1:3 (JZL184:diclofenac) were administered 120 min prior to testing. Data are expressed as mean ( \pm ) SEM. $(\mathrm{n}=10) . * \mathrm{p}<.05$ versus vehicle, ${ }^{* *} \mathrm{p}<.01$ versus vehicle, Dunnett post hoc. 


\section{Mechanical Allodynia}

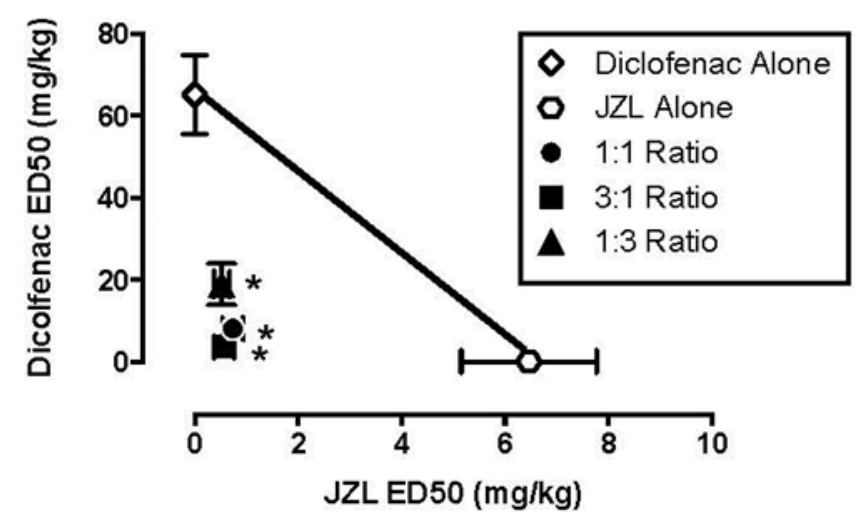

Cold Allodynia

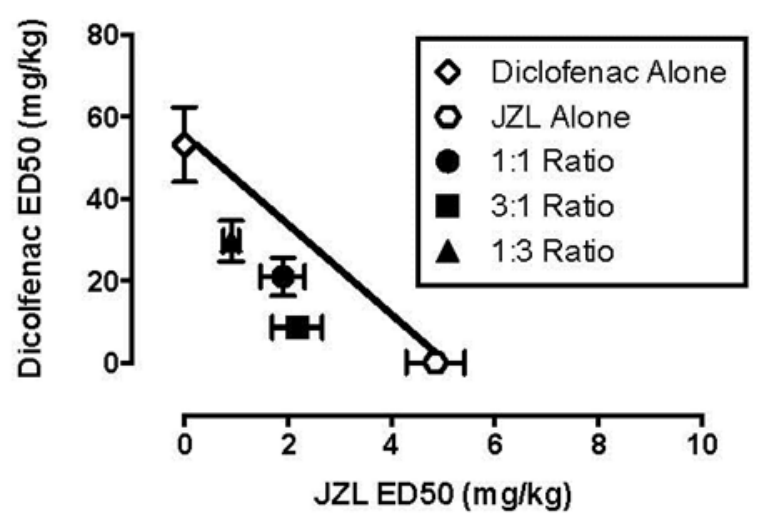

Figure 5. Coadministration of JZL184 and diclofenac sodium elicits synergistic analgesia in the mechanical allodynia test and additive analgesia in the cold allodynia test. Isobologram of the interactions between JZL184 and diclofenac in the CCI-induced allodynia model. The $\mathrm{ED}_{50}$ values for JZL184 and diclofenac are depicted on the $x$ and $y$ axes, respectively. The isobole of additivity is shown as a solid line connecting the $\mathrm{ED}_{50}$ values of JZL184 and diclofenac and depicting the theoretical line of additivity. The experimental $\mathrm{ED}_{50}$ values with $95 \%$ confidence interval of mixtures of JZL184 and diclofenac at fixed-ratio combinations of 1:1, 3:1, and 1:3 were significantly below the theoretical isoboles of additivity in the mechanical allodynia test, indication of a synergistic interaction. The experimental $\mathrm{ED}_{50}$ values in the cold allodynia test do not differ significantly than the theoretical isobole, and thus the interaction is considered additive. ${ }^{*} \mathrm{p}<.05$ ( $\mathrm{n}=10$ mice/treatment group). 